\title{
O IMPACTO DE UM MESTRADO PROFISSIONAL EM ENSINO DE FÍSICA NA PRÁTICA DOCENTE DE SEUS ALUNOS: UMA ANÁLISE BAKHTINIANA SOBRE OS SABERES PROFISSIONAIS
}

\begin{abstract}
RESUMO: Este trabalho tem por objetivo analisar o impacto de um mestrado profissional em ensino de Física na vida profissional de seus alunos, a partir dos conceitos de saberes e de conhecimentos profissionais cunhados, respectivamente, por Tardif (2007) e Porlán; Rivero (1998). A pesquisa foi realizada de acordo com uma análise qualitativa e a discussão dos dados foi feita com base no pensamento sobre análise do discurso do filósofo russo Mikhail Bakhtin (2003). Uma das etapas da investigação foi a entrevista semiestruturada, realizada com vinte alunos em diferentes situações em relação ao curso. Os resultados sugerem que as ações envolvidas na prática pedagógica dos alunos desde a questão curricular, passando pelo planejamento, crenças e concepções, estão impregnadas de elementos do racionalismo técnico, os quais o curso de mestrado profissional não parece abalar.

Palavras-chave: Mestrado profissional. Conhecimentos profissionais. Formação de professores.
\end{abstract}

THE IMPACT OF A PROFESSIONAL MASTER IN PHYSICS EDUCATION IN THE TEACHING PRACTICE OF THE STUDENTS: A BAKHTINIAN ANALYSIS ON PROFESSIONAL KNOWLEDGE

ABSTRACT: This work aims to analyze the impact of a Professional Master's in Physics Teaching in the professional life of their students throughout the concepts of knowledge and professional knowledge coined respectively by Tardif (2007) and Porlán and Rivero (1998). The investigation is qualitative, based on discourse analysis of Bakhtin (2003). One of the stages of the research presented here is based on semi-structured interviews conducted with twenty students in different situations in relation to the course. The findings suggest that the actions involved in the teaching practice of students concerning curriculum, planning, concepts and beliefs, are steeped in elements of the so called technical rationalism, which the Professional Master's degree does not seem to shatter.

Keywords: Master's degree. Professional knowledge. Teacher training.

\author{
Eliane Dias Alvarez Schäfer* \\ Fernanda Ostermann** \\ *Doutoranda em ensino de \\ Física pela Universidade Federal \\ do Rio Grande do Sul (UFRGS). \\ Professora de Física do Colégio de \\ Aplicação da Universidade Federal \\ do Rio Grande do Sul (UFRGS). \\ E-mail: elianealvarez@hotmail.com \\ * * Doutora em ensino de Física \\ pela Universidade Federal do \\ Rio Grande do Sul (UFRGS). \\ Professora Associado III do \\ Departamento de Física da \\ Universidade Federal do Rio \\ Grande do Sul (UFRGS). \\ E-mail: fernanda.ostermann@ufrgs.br
}




\section{INTRODUCุ̃̃O}

Em outubro de 17/10/1995, a Coordenação de Aperfeiçoamento de Pessoal de Nível Superior (CAPES), por meio da Portaria $n^{\circ} 47$, publicou a resolução 01/95 regulamentando procedimentos de recomendação, acompanhamento e avaliação de cursos de mestrado dirigidos à formação profissional, associada ao documento intitulado "Programa de Flexibilização do Modelo de pós-graduação Senso Estrito em nível de mestrado". Tal resolução foi revogada pela Portaria $\mathrm{n}^{\circ} 80$, de 16 de dezembro de 1998, que dispõe sobre o reconhecimento dos mestrados profissionais (MPs) e reitera a necessidade da formação de profissionais pós-graduados. (Severino, 2006, p. 10). A partir da publicação da Portaria Normativa $n^{\circ} 7$, artigo $n^{\circ} 2$, de 22 de Junho de 2009, o mestrado profissional (MP) foi situado dentro do contexto da pós-graduação, em que é atribuído ao detentor do título do MP os mesmos direitos dos portadores da titulação nos cursos do Mestrado Acadêmico (MA). (BRASIL (a), 2009, p. 31-32). Na portaria Normativa n ${ }^{\circ} 17$, de 28 de Dezembro 2009, esse trecho de igualdade de direitos é retirado, bem como o tempo máximo de titulação que era de dois anos (BRASIL (b), 2009, p. 20-21).

Em 2008 foi aprovado pelo Conselho Técnico Científico (CTC) do Ensino Superior, em sua $104^{a}$ reunião, um documento emitido junto à diretoria de avaliação da CAPES/DAV1 denominado "Ficha de Avaliação de programa de Mestrado Profissional", para o triênio de 2008-2010. Nesse documento, é apresentado o conceito do MP como sendo "[...] uma modalidade de formação pós-graduada stricto sensu que objetiva a capacitação para a prática profissional transformadora com foco na gestão, produção ou aplicação do conhecimento, visando à solução de problemas ou proposições de inovações [...]" (BRASIL, 2008, p. 1).

$\mathrm{Na}$ "Ficha de Avaliação de programa de Mestrado Profissional", o MP é citado como de fundamental relevância social e científica por isso,

"é necessária a implantação de um sistema de avaliação que considere suas especificidades, que valoriz̨e as iniciativas pertinentes à modalidade e que seja indutor de ajustes visando adequação de programas existentes às características desta modalidade de formação pós-graduada"

Esse documento apresenta as diretrizes e critérios para a avaliação e acompanhamento dessa modalidade de mestrado. Dentre esses critérios, são apresentados cinco quesitos para a avaliação do programa: Proposta do curso; Corpo Docente; Corpo Discente e Trabalhos de Conclusão; Produção Intelectual e Profissional Destacada; Inserção Social (BRASIL, 2008, p. 1).

O mestrado profissional (MP) é uma modalidade de formação "stricto sensu", inicialmente proposta como uma alternativa ao mestrado acadêmico (MA). Tem como objetivo suprir as demandas sociais, políticas e econômicas associadas à qualificação de trabalhadores em serviço (OSTERMANN; REZENDE, 2009).

Fischer $(2005$, p. 25, 29), ao descrever o MP, relata que este nasceu atrelado 
ao formato tradicional da concepção acadêmica de pós-graduação e, portanto, haveria uma "necessidade" de repensar sua avaliação a partir de novos parâmetros. $\mathrm{O}$ autor afirma que os mestrados profissionais (MPs) são experiências muito ricas que podem propiciar a reinvenção das práticas acadêmicas.

Negret (2008, p. 219) afirma que do MP pode resultar "uma maior aproximação entre a universidade e a realidade social". Dentro desse contexto, o maior desafio é integrar rigor à pesquisa e aplicabilidade dos resultados à sociedade. De acordo com o autor, o impacto dos MPs como resultado de sua inserção na sociedade deve ser medido, necessariamente, a partir de uma avaliação investigativa.

No que se refere a uma análise crítica dessa modalidade no contexto escolar, Ostermann; Rezende (2009, p. 69) sugerem que é necessária “[...] uma reflexão aprofundada sobre a natureza dos cursos de mestrado profissional em ensino (MPE) e sobre o possível impacto na sociedade brasileira [...]", pois ainda é uma questão ausente na produção acadêmica das áreas de Educação e Educação em Ciências.

A partir dessas orientações e entendendo que o aluno do mestrado profissional em ensino de Física (MPEF) é um sujeito histórico, imerso em um contexto sociocultural e detentor de saberes e conhecimento profissional docente, foi elaborado este trabalho de investigação, cujo objetivo é analisar o impacto de um curso de MPEF de uma universidade federal na vida profissional de seus alunos, a partir dos conceitos de saberes e de conhecimentos profissionais cunhados, respectivamente, por Tardif (2007) e Porlán; Rivero (1998). O delineamento metodológico foi baseado na investigação qualitativa, e a análise de discurso fundamentada nos conceitos translinguísticos apresentados por Bakhtin (2003). Para tanto, são previstas diferentes abordagens, tais como entrevista semiestruturada, estudo de caso e análise documental (a partir das dissertações de mestrados do MPEF).

Neste artigo, serão apresentados os resultados parciais da primeira etapa de investigação, que se constituiu em uma análise dos enunciados resultantes das entrevistas semiestruturadas, realizadas com vinte alunos que aqui serão denominados como alunos-professores (APs), pois também são docentes da educação básica. Foram utilizadas perguntas direcionadas ao planejamento e à dinâmica de trabalho em aula, ao currículo de Física nas escolas e à percepção do aluno-professor (AP) quanto ao MPEF. Este trabalho pretende contribuir, a partir do estudo do impacto de um curso de MPEF, para melhorias relacionadas a essa modalidade de formação.

\section{REFERENCIAL TEÓRICO E METODOLÓGICO}

Nesta pesquisa são utilizadas, como fundamentação teórica, epistemológica $^{3}$ e metodológica, as ideias de Tardif (2007) e Porlán e Rivero (1998), sendo que estas são particularmente empregadas na conceitualização do saber docente, assim como na definição das categorias de análise deste trabalho. 


\section{0 conhecimento profissional dos professores segundo Porlán e Tardif}

De acordo com Porlán, Rivero; Martín (1997), o conhecimento profissional pode ser entendido como um conjunto de concepções epistemológicas, ou seja, como:

[...] o resultado de justaposição de quatro tipos de saberes de natureza diferente, gerados em momentos e contextos nem sempre coincidentes, que se mantêm relativamente isolados uns dos outros, na memória dos sujeitos, e que se manifestam em distintos tipos de situação profissional ou pré-profissional (p.158).

De acordo com Porlán; Rivero (1998), o conhecimento real pode ser descrito a partir de quatro componentes que dão conta de construir um saber coerente com as demandas da atividade profissional, atendendo duas dimensões epistemológica e psicológica. Essas componentes são: os saberes acadêmicos, os saberes baseados nas experiências, as rotinas e guias de ação e as teorias implícitas (PORLÁN; RIVERO, 1998, p. 60).

Tardif (2007) interpreta o conhecimento docente como um saber plural, formado pelo amálgama de saberes oriundos da formação profissional, de saberes disciplinares, de saberes curriculares e de saberes das experiências. A partir dessa concepção, o saber profissional será o resultado da confluência entre várias fontes de saberes provenientes de vários lugares, de diversas situações, de acordo com contexto histórico e social de cada indivíduo:

[...] A idéia de base é que esses "saberes" (esquemas, regras, hábitos, procedimentos, tipos, categorias, etc.) não são inatos, mas produzidos pela socialização, isto é, através do processo de imersão dos indivíduos nos diversos mundos socializados (famílias, grupos, amigos, escola, etc.), nos quais eles constroem, em interação com os outros, sua identidade pessoal e social (TARDIF, 2007, p. 64, 71).

Tardif procura "estabelecer articulação entre os aspectos sociais e individuais dos saberes dos professores" e entende que o saber é social, "embora sua existência dependa dos professores (mas não somente deles) enquanto atores individuais empenhados numa prática" (TARDIF, 2007, p. 11). Ou seja, apesar de assumir que o saber é profundamente social, o autor defende que é impossível compreender a natureza desse saber sem colocá-lo em relação ao professor como um ser individual que o detém.

Nesse trabalho, os conceitos de saberes e conhecimentos profissionais docentes presentes nas obras de Tardif (2007) e Porlán; Rivero (1998) foram utilizados como fundamentação teórica na elaboração das categorias de análise relacionadas ao objetivo da investigação, descritas na seção de metodologia.

\section{Teoria da linguagem em Bakhtin}

Segundo o filósofo russo Mikhail Bakhtin (2003), o emprego “da língua efetua-se em forma de enunciados (orais e escritos), concretos e únicos, que emanam dos integrantes duma ou doutra esfera da atividade humana" e são caracteri- 
zados pelo conteúdo (temático), por seu estilo verbal e, sobretudo, por sua construção composicional (p. 261, 262). O conteúdo temático está associado ao domínio de sentido do texto; o estilo de linguagem (verbal) corresponde "ao conjunto de procedimentos de acabamento de um enunciado", ou seja, são os recursos lexicais, fraseológicos e gramaticais da língua utilizados para elaborar o enunciado e que criam "um efeito de sentido de linguagem do autor que é o que denominamos de efeito de individualidade" (FIORIN, 2006, p. 62, 46; BAKHTIN, 2003, p.261). A construção composicional está relacionada ao tipo de estruturação, ou organização, do enunciado e de acabamento, ou seja, é o "tipo de relação entre o locutor e os outros parceiros da comunicação verbal” (BAKHTIN, 2003, p. 266). Esses três elementos estão indissoluvelmente relacionados no todo do enunciado, "e todos eles são marcados pela especificidade de uma esfera de comunicação". É essa especificidade que evidencia a existência de um dado gênero, “ou seja, um dado tipo de enunciado relativamente estável do ponto de vista temático, composicional e estilístico". (BAKHTIN, 2003, p. 266) Associados a cada enunciado, portanto, existirão gêneros discursivos que são "tipos de enunciados relativamente estáveis" que se encontram sempre vinculados a domínios da atividade humana, "refletindo suas condições específicas e suas finalidades” (FIORIN, 2006, p. 61, 62).

De acordo com Bakhtin (apud WERTSCH, 1991), os enunciados existem apenas no contato dialógico com outros enunciados, portanto, são impregnados de nuances dialógicas. Ao analisar esses diálogos, é possível encontrar diferentes enunciados, mediadores de vozes originadas nas interações entre os sujeitos. Bakhtin (2006) apresenta o sentido amplo de diálogo como uma das formas mais importantes da comunicação verbal, e entende que o ato de fala, "ou mais exatamente, seu produto, a enunciação", não pode ser considerado de modo individual, pois sua natureza é social (p. 117, 103). Na visão do autor, em cada enunciado existirá a voz de quem fala e, possivelmente, a interação de outras vozes, organizadas socialmente. O conceito de voz, nesse caso, "não implica apenas a comunicação oral, mas também a escrita e abrange as impressões, o conhecimento adquirido ao longo da vida e visões do mundo do sujeito" (BORGES; REZENDE, 2010, p. 6). Em uma situação de polifonia, "o todo é a interação das diversas consciências numa justaposição, num contraponto, numa simultaneidade" e fica evidente a equipolência das vozes, ou seja, "um mundo polifônico seria um mundo em que o pluralismo de idéias fosse efetivamente respeitado, porque todas as vozes seriam eqüipolentes, nenhuma voz social se imporia como palavra última e definitiva" (FIORIN, 2006, p. 82, 83). Por outro lado, a monofonia corresponde à situação em que uma voz domina as outras vozes (RECHDAN, 2003, p. 2).

Bakhtin (2003), em seu trabalho sobre o romance de Dostoiévski, percebe a importância do papel do autor da obra, definindo-o como: "[...] o agente da unidade tensamente ativa do todo da obra, e este é transgrediente a cada elemento particular desta.” (p.10). A partir dessa concepção, são apresentados três tipos: o autor-pessoa - que é o criador ativo, ou seja, quem fala; o autor-criador - que está associado a fatores aleatórios que condicionam as declarações do 
autor-pessoa, ou seja, valores, credos, visão social, etc.; e o personagem - que é criado pelo autor (p. 6).

Neste trabalho são utilizados conceitos, presentes na obra de Bakhtin, como suporte teórico-metodológico para a compreensão dos enunciados, precedidos de nuances dialógicas para a identificação do autor e dos gêneros discursivos. Também será buscada a presença de vozes que levam à concepção de polifonia ou monofonia dos enunciados, resultantes das entrevistas realizadas com os APs.

\section{METODOLOGIA}

O presente estudo caracteriza-se por ser uma pesquisa qualitativa, acompanhada de um extenso aprofundamento teórico-metodológico, e foi desenvolvido com 20 alunos-professores (APs) de um curso de mestrado profissional em ensino de Física de uma instituição federal de Ensino Superior. Os APs apresentavam-se em diferentes situações em relação ao curso, sendo elas categorizadas por alunos novos, ou seja, ingressantes no MPEF em 2011/1; alunos egressos, que já haviam finalizado o curso; alunos regulares do MPEF; e outros, categoria composta por ex-alunos do MPEF: pelos seguintes motivos: abandono do curso, desligamento a pedido do aluno ou desligado do curso por limite de prazo.

A tabela 1 apresenta informações que caracterizam os sujeitos em relação ao curso quanto ao tempo de profissão no momento de inscrição no MPEF, quanto à idade (em anos), quanto à carga horária semanal na escola durante o curso e quanto à experiência profissional.

Como mediadora das ações investigativas foi realizada uma entrevista semiestruturada, gravada em áudio. Para a realização dessa entrevista, foi elaborado um guia constituído por 34 perguntas, dividido em três blocos (ou critérios): I) oito perguntas que contemplam os aspectos observados na estruturação da prática pedagógica dos APs; II) dez perguntas que tratam das crenças ou concepções presentes na fala dos APs e encontram-se em fase de análise, não fazendo parte deste trabalho; III) dezesseis perguntas que tratam da relação entre a formação no MPEF e a prática pedagógica dos APs.

O roteiro da entrevista foi elaborado a partir da definição dos objetivos inicialmente apresentados e da leitura de trabalhos que buscam entender, descrever e analisar contextos da sala de aula, além de investigar as concepções e os saberes profissionais e traçar o perfil docente, empregando como método de coleta de dados entrevistas e questionários (SOCORRO; MACEDO; MORTIMER; GUIMARÃES; ECHEVERRÍA; MORAES, 2006).

Esse instrumento foi validado a partir da revisão de cinco especialistas que julgaram a representatividade dos itens em relação ao conteúdo e a relevância dos objetivos a medir. Após as correções e ajustes necessários, o guia foi submetido novamente ao julgamento de dois especialistas. 
Tabela 1: Síntese das informações referentes aos APs.

\begin{tabular}{|c|c|c|c|c|c|}
\hline $\begin{array}{l}\text { Professor } \\
\text { (AP) }\end{array}$ & Idade (anos) & $\begin{array}{c}\text { Situação no } \\
\text { curso }\end{array}$ & $\begin{array}{c}\text { Tempo de } \\
\text { profissão ao } \\
\text { se inscrever } \\
\text { no MPEF }\end{array}$ & $\begin{array}{c}\text { Carga } \\
\text { horária } \\
\text { semanal do } \\
\text { professor } \\
\text { na escola } \\
\text { durante o } \\
\text { MPEF }^{4}\end{array}$ & $\begin{array}{c}\text { Experiência } \\
\text { profissional } \\
\text { dos APs } \\
\text { (Instituição) }^{5}\end{array}$ \\
\hline P1 & 26 & Egresso & 1 ano & 15 horas & Priv./Públ. \\
\hline P2 & 27 & Novo & 3 anos & 10 horas & Pública \\
\hline P3 & 44 & Egresso & 12 anos & 35 horas & Privada \\
\hline P4 & 56 & Egresso & 29 anos & 2 horas & Priv./Públ. \\
\hline P5 & 25 & Aluno & 1 ano & 14 horas & Pública \\
\hline P6 & 35 & Outro & 8 anos & $\mathrm{NI}$ & Priv./Públ. \\
\hline P7 & 31 & Egresso & 4,5 anos & 40 horas & Pública \\
\hline P8 & 50 & Aluno & 15 anos & 29 horas & Priv./Públ. \\
\hline P9 & 31 & Aluno & 9 anos & 40 horas & Priv./Públ. \\
\hline P10 & 32 & Novo & 3 anos & 20 horas & Pública \\
\hline P11 & 24 & Novo & 2 anos & 9 horas & Privada \\
\hline P12 & 30 & Novo & 7 anos & 50 horas & Priv./Públ. \\
\hline P13 & 30 & Novo & 8 anos & 38 horas & Priv./Públ. \\
\hline P14 & 33 & Novo & 13 anos & 38 horas & Privada \\
\hline P15 & 39 & Egresso & 2 anos & 52 horas & Priv./Públ. \\
\hline P16 & 32 & Novo & 2 anos & 31 horas & Pública \\
\hline P17 & 29 & Aluno & 1 ano & 14 horas & Pública \\
\hline P18 & 42 & Outro & 4 anos & 30 horas & Pública \\
\hline P19 & 28 & Outro & 2 anos & 14 horas & Priv./Públ. \\
\hline \multirow[t]{2}{*}{ P20 } & 30 & Aluno & 9 anos & 10 horas & Pública \\
\hline & $\begin{array}{l}\text { Média: } \\
33,85\end{array}$ & & $\begin{array}{l}\text { Média: } \\
\text { 6,77 }\end{array}$ & $\begin{array}{c}\text { Média }: \\
\text { 25,84 horas }\end{array}$ & \\
\hline
\end{tabular}

Neste trabalho, serão apresentadas as análises dos enunciados dos APs em relação às seguintes perguntas:

Bloco I: Quais fatores são relevantes quando você elabora o seu plano de aula? Como são determinados quais conteúdos de Física serão trabalhados em cada série, em sua escola? Como é a sua dinâmica de trabalho em aula? (grupos, individual, quadro, apostila, experimentos, etc.). 
Bloco III: Em sua percepção, qual a diferença entre a realidade escolar e a formação recebida no MPEF? Explique. Em sua opinião, quais assuntos trabalhados no MP podem ser utilizados em uma transposição didática para o seu trabalho dentro do contexto escolar? A partir do que foi trabalhado no MPEF, o que mudou em sua prática dentro do contexto escolar?

Essas perguntas foram selecionadas visando estudar as categorias de análise (diferenciação de conteúdo, formativa-pedagógica e técnica). O objetivo é, a partir dessa análise, entender, inicialmente, o impacto do mestrado profissional na vida profissional do AP, a partir da descrição de suas práticas dentro do contexto escolar, na percepção quanto às possíveis diferenças entre a realidade escolar e a academia, também quanto à possibilidade de aplicação e transposição didática dos materiais e conteúdos trabalhados no MP em atividades em sala de aula. Além disso, a partir dos enunciados resultantes da relação dialógica, buscou-se identificar quais saberes permeiam suas falas, utilizando as seguintes questões mediadoras: quais saberes e conhecimentos profissionais são comuns aos APs? Quais saberes ou conhecimentos profissionais estão presentes na descrição de suas práticas? O Quadro 1 apresenta, de forma esquemática, as questões de investigação, as questões mediadoras, os referenciais adotados, os critérios observados e as categorias analisadas.

\section{Categorias de análise}

As categorias diferenciação de conteúdo, formativa-pedagógica e técnica, utilizadas neste trabalho, foram elaboradas a partir do entendimento de que o AP é um sujeito histórico, imerso em um contexto sociocultural, detentor de saberes e conhecimento profissional docente. Essas categorias, conforme mencionado anteriormente, emergem dos conceitos de saberes e conhecimentos profissionais docentes cunhados por Tardif (2007) e Porlán; Rivero (1998).

Quadro 1: Questões de investigação e aspectos estruturais da pesquisa.

\begin{tabular}{|c|c|c|c|c|}
\hline $\begin{array}{l}\text { Questões de } \\
\text { pesquisa: } \\
\text { objeto de } \\
\text { investigação }\end{array}$ & $\begin{array}{l}\text { Critérios ou } \\
\text { blocos de } \\
\text { interesse }\end{array}$ & $\begin{array}{l}\text { Categorias de } \\
\text { análise }\end{array}$ & $\begin{array}{l}\text { Referencial } \\
\text { teórico }\end{array}$ & $\begin{array}{c}\text { Questões } \\
\text { mediadoras de } \\
\text { pesquisa }\end{array}$ \\
\hline \multirow{3}{*}{$\begin{array}{l}\text { Qual o impacto } \\
\text { do mestrado } \\
\text { profissional na } \\
\text { vida profissional } \\
\text { do AP? }\end{array}$} & \multirow{3}{*}{$\begin{array}{c}\text { I) Aspectos } \\
\text { observados na } \\
\text { estruturação } \\
\text { da prática } \\
\text { pedagógica } \\
\text { segundo os APs } \\
\text { III) Relação } \\
\text { entre a } \\
\text { formação no } \\
\text { MPEF e o fazer } \\
\text { pedagógico } \\
\text { segundo o AP. }\end{array}$} & $\begin{array}{l}\text { Diferenciação } \\
\text { de Conteúdo }\end{array}$ & \multirow{3}{*}{$\begin{array}{c}\text { Tardif (saberes) } \\
\text { e Porlán } \\
\text { (conhecimento) }\end{array}$} & \multirow{3}{*}{$\begin{array}{c}\text { Quais saberes e } \\
\text { conhecimentos } \\
\text { profissionais } \\
\text { são comuns aos } \\
\text { APs do MPEF? } \\
\text { Quais } \\
\text { saberes ou } \\
\text { conhecimentos } \\
\text { profissionais } \\
\text { estão presentes } \\
\text { na descrição de } \\
\text { suas práticas? }\end{array}$} \\
\hline & & $\begin{array}{l}\text { Formativa } \\
\text { Pedagógica }\end{array}$ & & \\
\hline & & Técnica & & \\
\hline
\end{tabular}


A primeira categoria analisada procura entender as diferenças entre os conteúdos apresentados durante o MP e os que são, realmente, trabalhados em sala de aula, ou seja, que fazem parte do currículo escolar. Denominamos essa categoria como diferenciação de conteúdo. Ela está fundamentada nos saberes disciplinares que são "saberes sociais definidos e selecionados pela instituição universitária”, ou seja, Física, Química, Literatura, etc.; nos saberes curriculares que "correspondem aos discursos, objetivos, conteúdos e métodos, a partir dos quais a instituição escolar categoriza e apresenta os saberes sociais por ela definidos e selecionados como modelo de cultura erudita” (TARDIF, 2007, p. 38). Também é fundamentada nos saberes acadêmicos que se referem "ao conjunto de concepções disciplinares que os professores têm, sejam estas relativas aos conteúdos do currículo ou das ciências da educação". Tais saberes são nomeados e identificados, “desdenhosamente”, como “a teoria” (PORLÁN; RIVERO, 1998, p. 60).

A segunda categoria é denominada como formativa-pedagógica. O objetivo dessa categoria é analisar o estabelecimento de relações entre a formação teórica, epistemológica e metodológica, propiciada pelo MP, e a prática do professor. Essa categoria é fundamentada nos saberes acadêmicos (PORLÁN; RIVERO, 1998, p. 60) e nos saberes da formação profissional, que é "o conjunto de saberes transmitidos pelas instituições de formação de professores", ou seja, são os saberes "pedagógicos" que se apresentam "como doutrinas ou concepções provenientes de reflexões sobre a prática educativa no sentido amplo do termo”. A função desses saberes é normatizar, conduzir e orientar a atividade educativa (TARDIF, 2007, p. 36, 37). Para a análise dessa categoria, foram comparados os saberes acadêmicos e os saberes da formação profissional àqueles originados na experiência docente. Os saberes da experiência correspondem "ao conjunto de idéias conscientes que os professores desenvolvem durante o exercício da profissão" e que correspondem ao conhecimento do "senso comum" (PORLÁN; RIVERO, 1998, p. 60). Também são considerados como saberes práticos, que são incorporados "à experiência individual e coletiva sob a forma de habitus e de habilidades, de saberfazer e de saber-ser" (TARDIF, 2007, p. 38).

A terceira categoria é denominada técnica. Ela procura identificar elementos associados ao conceito de racionalismo técnico, cuja epistemologia "repousa na ideia de que um conhecimento profissional é um conhecimento aplicado que se fundamenta hierarquicamente em princípios gerais ao mais alto nível, e ao mais baixo nível na resolução de problemas concretos" (TARDIF; LESSARD; GAUTHIER, 2001, p. 19). De acordo com Contreras (2002, p. 90), “a idéia básica do modelo de racionalidade técnica é que a prática profissional consiste na solução instrumental de problemas mediante a aplicação de um conhecimento teórico e técnico, previamente disponível, que procede da pesquisa cientifica”. Nessa concepção, o professor busca a solução ou os resultados desejados a partir da aplicação de técnicas e procedimentos que instrumentalizam ou justificam esse efeito.

Essa categoria está fundamentada nos saberes curriculares (TARDIF, 2007, p. 38), nos saberes originados na experiência docente (PORLÁN; RIVERO, 
1998, p. 60; TARDIF, 2007, p. 38) e nas rotinas e guias de ação, que se referem “ ao conjunto de esquemas tácitos que predizem o curso dos acontecimentos em aula e que contêm pautas de atuação concretas". Tal categoria é resistente à mudança e está relacionada a perguntas do tipo "o que fazer nesta determinada situação?" ou “como fazer?” (PORLÁN; RIVERO, 1998, p. 61).

\section{RESULTADOS}

Nesta seção são apresentados extratos dos discursos, a partir de orações que representam o todo do enunciado completo. A seleção dos enunciados apresentados seguiu os seguintes critérios: clareza, detalhamento e representatividade das respostas. A partir desse critério, foram selecionados extratos de enunciados, para uma mesma pergunta, com o mesmo conteúdo temático, ou seja, a mesma significação, o mesmo tema e o mesmo domínio de sentido em relação à pergunta. Os termos ou expressões sublinhados correspondem aos achados fundamentais para a análise, em cada enunciado. Os termos entre colchetes com reticências "[...]" correspondem a palavras ou expressões que foram retiradas sem perda de sentido da frase, ou que poderiam, de alguma forma, permitir a identificação do AP por seus pares, ou por professores do MPEF. As reticências “...” significam pausa na fala, ou seja, intervalo de tempo.

\section{Categoria diferenciação de conteúdo}

3) Como são determinados quais conteúdos de Física serão trabalhados em cada série, em sua escola? P4 - "bem livresca [...] então se estabelecia o que era um conteúdo fundamental, ou quais eram as necessidades básicas para o aluno ao final do segundo grau. Então tinha um preestabelecido, e se tu pega e fizer um levantamento, muitos deles são marcados pela descrição que ocorre nos livros, né? Então a gente sempre escolbia bons livros, os bons livros, na realidade, eram aqueles que contemplavam aquela sequencia de conteídos que tu considerava importante."

P6 - "São determinados de acordo com o que as editoras dizem que é pra gente trabalhar [...]"

P3 - "Bem, todo ano a gente para pra pensar sobre isso e todo ano nós mudamos a grade curricular, tá? Então cada vez mais nós olhamos o que os vestibulares esperam da gente, o que o ENEM espera da gente enquanto conbecimento fundamental [...]" P14 - "Ah, isso é vertical...vertical de cima para baixo não tem muito o que mudar, eu não tenho é...autonomia, euu não tenho autonomia [...] nem de mudar a ordem, eu não posso mudar a ordem [...]"

O conteúdo temático desses enunciados corresponde à determinação dos conteúdos de Física que são trabalhados na educação básica, em cada série. A construção composicional (organização) dos enunciados parece obedecer a uma sequência lógica: resposta, justificativa ou contextualização e conclusão. Nesse esquema há o livro e a editora, como resposta; a experiência, como justificativa ou contextualização; e o posicionamento pessoal, como conclusão.

Os enunciados refletem a autoria de quem fala, ou seja, o autor-pessoa, a partir da utilização do "eu". Em diversos momentos é empregada a expressão "a gente" como um recurso da linguagem que reflete a necessidade do AP de compartilhar a responsabilidade, em relação às decisões, com outros professores, e de buscar a solidariedade da entrevistadora, que também é professora. 
A análise dos enunciados evidencia uma monofonia, ou seja, há uma voz (autoritária) relacionada aos saberes definidos pela escola e de seu compromisso com o que preconizam os livros didáticos, o ENEM e o vestibular, resultando na determinação de quais conteúdos serão trabalhados e em que ordem. Os enunciados refletem a importância dos saberes curriculares e disciplinares definidos pelas escolas a partir da imposição dos mesmos discursos, objetivos, conteúdos e métodos.

31) Em sua opinião, quais assuntos trabalhados no MP podem ser utilizados em uma transposição didática para o seu trabalho dentro do contexto escolar?

$P 1$ - "Eu acho que a maioria, né? Dos assuntos, tanto a parte de Física Geral, quanto boa parte da Física Moderna e Contemporânea, que a gente abordou no mestrado profissional, podem ser levadas pra sala de aula [...]"

P3 - "Bom, a gente tá buscando até hoje fazer uma transposicão de quântica, né? Estamos buscando até hoje fazer uma transposição de relatividade e já fizemos, esta sim, uma transposição de astronomia [...]"

P9 - "[...] todas têm alguma coisa que pode ser jogada [...] agora o nivel da disciplina ela, ele é bem acima daquilo que a gente vai aplicar em sala de aula [...] daqui a pouco a gente tá calculando o cálculo integral e tal, e tem muita gente que nem se lembra disso, né?[... tá muito distante da sala de aula [...]"

P19 - "[... Ta gente não estudava nada que estivesse desvinculado da Física, estudando Física e a forma como era apresentada, na grande maioria dos casos, ela te permitia levar aquelas ideias, claro, passando por um tratamento adequado para considerar o nivel de cada aluno, mas de levar isso para a sala de aula, [...] claro, entra a funcão do professor também, nós estávamos tendo uma aula de mestrado, mestrado para o Ensino Médio, mas é completamente possivel essa transposição."

P20 - "Bem, principalmente a parte de tecnologia da educacão e informacão e a parte da Fúsica Moderna que veio, principalmente, aquela a parte do [...] bom, na realidade todos eles en vou ter que fazer, en acho que é tudo o que a gente aprendeu foi muito importante, entendeu?"

O conteúdo temático desses enunciados está associado à aplicabilidade dos assuntos trabalhados no MP, a partir de uma transposição didática, no contexto escolar. A construção composicional dos enunciados parece iniciar com a retomada das disciplinas que são, ou foram, representativas, passando pela análise dessas disciplinas e finalizando com considerações particulares.

São empregadas as expressões "eu acho”, “a gente tá buscando" e "alguma coisa pode ser jogada”, como um recurso linguístico que reflete a crença dos APs quanto à possibilidade de haver transposição didática, apesar de não saberem exatamente como. Nesses enunciados, a expressão "a gente" parece ser empregada como um recurso linguístico que busca o compartilhamento de sua posição em relação aos seus pares e, também, em relação à entrevistadora.

Estão presentes, nos enunciados, ecos de enunciados anteriores, oriundos, provavelmente, do MPEF, representados pelas expressões "quântica", "Física Moderna e Contemporânea" e "tecnologia da educação e informação". Essas expressões são palavras, ou uma combinação de palavras, de um gênero particular, caracterizadas por um estilo linguístico ou funcional, facilmente encontrado no MP.

De acordo com os enunciados, a formação propiciada pelo MP deveria fornecer subsídios teóricos, epistemológicos e metodológicos para que o aluno pudesse diversificar e qualificar sua prática, no entanto, a transposição didática parece depender do perfil do AP e das características pedagógicas da escola em que ele trabalha. 
Os enunciados refletem a problemática associada à dicotomia entre os saberes da experiência e os saberes acadêmicos, sendo que todos são fortemente marcados por uma orientação disciplinar (conteúdos), em diferentes níveis.

\section{Categoria formativa-pedagógica}

24) Em sua percepção, qual a diferença entre a realidade escolar e a formação recebida no MPEF? Explique.

P2 - " [...] não tem muita ligacão entre a prática escolar, aquele currículo da escola com a parte de teorias, isso eu não vejo muita ligacão, assim, mais de tecnologias de instrumentação, laboratório, isso eu vejo bastante ligação com a escola, a parte de teoria não consigo ver ainda [...]"

P5 - "Olha, na minha escola en acho que não teve assim, tipo, en dizer que as coisas que en aprendi aqui não dá pra fazer lá [...] agora eu imagino que escolas que sejam mais precárias, assim, tipo a formacão daqui, não é muito voltada para estas escolas."

P12 - "Na verdade, o MPEF, ele não tá [...] quem vai relacionar ele com a realidade escolar sou eu [...] o que o mestrado, acho, ele faz, é tentar um embasamento para que tu relacione isso [...] é tudo questão do nosso contexto, é eu, tipo, que vou ter que relacionar o men contexto de trabalho com o contexto que eston aprendendo aqui [...]"

P4 - É, aí vem problemas sérios, no MPEF se trabalha alunos, pra alunos que eles acreditam que existe, né? P18 - Megaparsecs de distância... [...] eu acho que enquanto se trabalhar com estas teorias idealizadas duma coisa que não existe, vai se encontrar uma situação que não existe, [...] que não tem lá fora, [...] eu acho que só vai dar certo 0 dia que o pessoal botar a cara para fora do Instituto [...]"

O conteúdo temático desses enunciados corresponde a uma breve análise quanto à diferença entre a realidade escolar e a formação recebida no MP, indicando a existência de um distanciamento entre as duas realidades. $\mathrm{Na}$ organização (construção composicional) dos enunciados, encontram-se dois pólos: de um lado, a realidade do próprio AP e, do outro, uma reflexão baseada nos problemas atuais das escolas. Esses argumentos estão baseados nos saberes da experiência, ou seja, na prática profissional, que é comparada à formação recebida no MP (saberes acadêmicos e da formação profissional).

Os enunciados evidenciam a autoria de quem fala, ou seja, o autor-pessoa, a partir da utilização do "eu”, como indivíduo social, e o autor-criador que reflete sobre as dificuldades encontradas nas escolas públicas da periferia, sobre o aluno real e a dificuldade de trabalhar com essa realidade.

O enunciado P18 sugere uma relação dialógica e social na qual estão presentes o autor da produção verbal (AP), o destinatário (entrevistadora) e o superdestinatário (MPEF). A palavra "megaparsecs" evidencia a relação do locutor com o outro (entrevistadora) e com seus enunciados, pois tal termo pertence a um gênero particular de vocabulário comum às ciências exatas (a entrevistadora também é professora de Física).

A análise dos enunciados evidencia um conflito entre os saberes oriundos da experiência profissional e os saberes acadêmicos, ou seja, os saberes da formação profissional.

33) A partir do que foi trabalhado no MPEF, o que mudou em sua prática dentro do contexto escolar? P7 - "[...] mudou em termos de a forma de abordar o conteúdo, a forma de avaliar, a forma de encarar o processo de ensino-aprendizagem [...]" 
P15 - "Ah, eu acho que mudou para eu trabalhar mais conceitualmente, isso ajudou bastante, não que eu não ache que o cálculo ainda não seja válido, acho que é, é porque a gente precisa de certos cálculos na vida, né? Mas acho que trabalhar mais conceitualmente, procurar trazer mais a realidade para a sala de aula e utilizar as novas tecnologias, eu não posso deixar isso de fora."

P5 - "Mudou muita coisa, assim mudou a questão de querer dar voz, assim, pro aluno, assim, de levar em consideração aquilo, assim, que ele fala, de tentar argumentar; é partindo daquilo que tá achando que sabe ou daquilo que ele sabe, mudou aquela questão [...] da epistemologia ciência, acho que se não fosse o MPEF en taria dizendo pros meus alunos que, tipo, se não é científico não vale a pena [...]"

O conteúdo temático desses enunciados evidencia a percepção do AP quanto ao impacto do MP em sua prática na sala de aula. Os enunciados estão organizados partindo de uma afirmação que indica que houve mudanças, seguida de uma justificativa contextualizada a partir da experiência.

O enunciado P5 apresenta ecos e lembranças de enunciados anteriores, originados no MPEF, representados pelas expressões "partindo daquilo que tá achando que sabe ou daquilo que ele sabe" e "da epistemologia ciência". Esse enunciado parece estar baseado nesses enunciados anteriores, confirmando-os.

Esses enunciados evidenciam saberes oriundos da formação profissional (saberes acadêmicos) em consonância com os saberes da experiência que parecem confundir-se em um discurso, ao serem descritas as mudanças decorrentes do MP na prática cotidiana.

\section{Categoria técnica}

2) Quais fatores são relevantes quando você elabora o seu plano de aula?

P2 - "[...] tentar diversificar a aula, eu tento, ahn, não ter só uma aula teórica, levar em conta o nível de atencão que eles vão ter [...]"

P8 - "Motivacão, conteúdo, tem que ver qual é o conteúdo que en vou focar, qual é a motivação, qual é o público alvo público-alvo [...]"

P10 - "O nivel de desenvolvimento dos alunos também, também busco diversificar minha aula, né? Tražendo alguns elementos diferentes, alguma demonstração ou uma simulação computacional, alguma coisa que diversifique a aula." P16 - "O aprendizado do aluno, como é que ele vai... abn, absorver aquele conbecimento ali que eu tô tentando passar para ele [...]"

P11 - "Primeiro o material que eu tenbo à disposicão, depois o que en quero ensinar, quais são os meus objetivos, assim." P1- "A continuidade natural dos conteúdos, a disposicão desses conteúdos no material didático, procurar também dispensar algum tempo a realização de exercício em sala de aula e procurar, também, diferenciar alguma atividades." P3 - "Bom, o primeiro fator é onde en quero chegar, né? Então eu acho que a aula, ela começa por um objetivo [...] o primeiro quesito é onde en quero chegar, depois qual tempo eu tenho? para chegar lá, né? Então o nivel de profundidade daquilo que vai ser discutido vai depender muito disso. Então meu planejamento, num primeiro momento, acho que são esses dois parâmetros fortes ai que eu uso."

O conteúdo temático desses enunciados está relacionado ao plano de aula. Os enunciados evidenciam que os principais objetivos dos APs, ao elaborarem o plano de aula, são: a motivação, o conteúdo, a diversidade dos métodos e o público-alvo (alunos). A organização desses enunciados parece iniciar com a apresentação dos fatores considerados importantes para o planejamento das aulas, passando para a justificativa ou descrição desses fatores e uma breve conclusão ou fechamento.

Os enunciados evidenciam a presença de palavras, ou de um conjunto de palavras, pertencentes a um gênero particular característico do campo da didática. 
Há uma monofonia (discreta) relacionada aos saberes definidos pela escola (saberes curriculares), que trata como objetivos de uma aula a motivação do aluno, a diversidade de métodos e a atenção do aluno.

P6 - "[...] e se, se eu falar que eu não planejo a aula, eu tô só [...] tô repetindo as mesmas aulas, eu tenho a aula toda na cabeça, não planejo as aulas [...]”"

P17 - "[...] eu vou ser bem sincero, eu não elaboro plano de aula [...] antes eu era mais centrado no livro didático $e$ agora eu puxo um tema e tento gerar em cima desse tema o conhecimento [...]"

P5 - "[...] quando eu tava fazendo o meu projeto do mestrado profissional eu era mais cuidadosa com isso, sabe? Tipo [...] eu fiz o projeto para aplicar em sala de aula, então eu levava muito as coisas em consideração, tipo, eu fazia com eles assim, é, primeiro buscava as ideias prévias deles, depois, tipo, eu buscava em casa argumentação, assim, pra discutir com eles em sala de aula. Agora, assim, que eu tô mais na correria, assim, tipo, não tô muito sentando e planejando tudo e tal, eu também levo em consideração o que eles já sabem, mas dai é uma coisa mais sistemática $[\ldots]$ ”

Esses enunciados refletem a problemática do racionalismo técnico, no qual o trabalho docente fica reduzido às tarefas rotineiras, aos objetivos e aos programas, sem necessidade de entendimento do "porquê", mas do "como". Essa realidade parece estar associada aos saberes curriculares e às rotinas escolares (rotinas e guias de ação).

4) Como é a sua dinâmica de trabalho em aula? (grupos, individual, quadro, apostila, experimentos, etc.)? P4 - "[...] quadro e gir, en fui preparado para isso, [...] embora sempre que houvesse oportunidade o trabalho em laboratório ou um trabalho em grupo, assim, que eles pudessem construir juntos, a gente aproveitava, mas não era a tônica [...]"

P14 - "[...] bastante quadro, uma aula bastante expositiva [...] basicamente quadro. [...] É eu tô repensando bastante as minhas práticas agora, depois de entrar no mestrado [...] lamento não ter tempo de formular as minhas aulas agora [...]"

P9 - "Ahn, essa é outra questão que, que envolve bem a metodologia da escola, mas pra mim... abn, a ideia é aula, tem que ser participada, então, mesmo numa aula expositiva, onde é eu que vou estar a maior parte do tempo falando com os alunos, a ideia é de vez em quando fazer perguntas e vendo o que eles sabem a respeito do tempo [...]"

P18 - "[...] a minha aula é [...] eu considero ela expositiva tradicional, né? Com o uso do livro [...]"

O conteúdo temático desses enunciados está direcionado à dinâmica da aula e ao seu planejamento, com ênfase nas particularidades individuais resultantes do contexto escolar ao qual o AP está inserido.

Nesses enunciados está presente um conjunto de palavras que pertencem a um gênero particular característico do campo da pedagogia, como os termos "repensar a prática", "aula expositiva" e "método tradicional".

Esses enunciados parecem estar baseados nos saberes da experiência e descrevem aulas tradicionais, discursivas, que priorizam a utilização de quadro e giz, bem como a fixação do conteúdo por meio de exercícios. Há forte indício de racionalismo técnico, como uma voz autoritária (monofônica), que dita como deve ser o trabalho do AP, ou seja, baseado na aplicação de rotinas, normas e métodos definidos pela escola (saberes curriculares e rotinas e guias de ação). 


\section{DISCUSSÃO}

Quanto ao impacto do mestrado profissional na vida docente do aluno-professor, a análise dos enunciados não permitiu identificar um conjunto de palavras que evidenciassem gêneros discursivos relacionados às teorias de ensino-aprendizagem e à epistemologia (temas abordados em disciplinas do curso), como, por exemplo, para a elaboração do plano de aula. Por outro lado, nesse caso, são considerados os conteúdos, os alunos, o nível de desenvolvimento dos alunos e a motivação. Esse resultando evidencia que os APs são subjugados aos saberes curriculares, ou seja, aos programas, objetivos, conteúdos e métodos determinados pela escola, cabendo ao professor aplicá-los, não havendo espaço, dentro da comunidade escolar, para decidir ou modificar o método de trabalho e o currículo, que fica atrelado aos livros didáticos, ao vestibular e, mais recentemente, ao ENEM. Desse planejamento, em geral, resultam aulas expositivas, tradicionais, com uso do quadro e do giz. Os enunciados também indicam que, em geral, os APs, independentemente de sua situação em relação ao curso, parecem estar sob forte influência dos saberes oriundos de sua própria experiência profissional, utilizando-se destes para respaldar suas ações, práticas e concepções. Apesar desses resultados, o discurso dos professores procurou defender a ocorrência de mudanças em suas práticas dentro do contexto escolar, particularmente "na forma de abordar o conteúdo", "trabalhar mais conceitualmente", "procurar trazer mais a realidade para a sala de aula", "utilizar as novas tecnologias", etc., ou seja, na visão de seus alunos, o MP parece contribuir na metodologia de trabalho em sala de aula.

$\mathrm{Na}$ contramão dos aspectos positivos apontados pelos APs quanto às mudanças ocorridas em suas práticas decorrentes da formação obtida, está o distanciamento entre a realidade escolar e a formação obtida no MP. Ou seja, o distanciamento aparece como uma situação real e complexa, que até o momento não foi solucionada, apesar de iniciativas dos docentes do MP (que tentam minimizar esse distanciamento) e da qualidade das disciplinas oferecidas pelo programa. Essa situação pode motivar conflitos entre os saberes preexistentes e os saberes oriundos da formação.

Quanto ao racionalismo técnico, ao serem analisados os processos descritos na prática pedagógica, desde a questão curricular, passando pelo planejamento, até as crenças e concepções presentes nessa prática, é possível identificar elementos associados às rotinas de ação e saberes da experiência, originados no contexto escolar. Os saberes oriundos da escola ficam "inseridos" nos saberes da experiência, a partir da rotina diária dos afazeres didático-pedagógicos. Com o passar dos anos, o professor tende a justificar sua prática a partir dos saberes da experiência, tomando como referência o saber-fazer. Os saberes sociais definidos pela escola apresentam fortes traços da racionalidade técnica que pode ser sintetizada a partir de três aspectos: a separação entre a concepção e a execução do processo, a desqualificação profissional e a perda do controle sobre seu próprio trabalho. A escola é responsável por normatizar os discursos, os objetivos, os conteúdos, os métodos, etc., a partir da determinação de rotinas direcionadas à aplicação e à atuação concreta de 
pautas. Esse resultado indica que a prática dos APs está impregnada de racionalismo técnico, ainda não superada pelos cursos de formação continuada, como o MP.

\section{CONCLUSÃO}

Os resultados encontrados, até o momento, indicam que, independentemente da situação em relação ao curso, os APs parecem estar sujeitos aos mesmos tipos de saberes oriundos das mesmas fontes. Esse resultado pode ser explicado pelo fato de que o professor da educação básica (AP), ao ingressar no MP, traz consigo experiências profissionais, associadas aos saberes oriundos da formação inicial, e saberes sociais definidos pela instituição na qual trabalha. Esses saberes, em geral, são fortemente marcados pela racionalidade técnica. Por outro lado, o MP almeja uma qualificação profissional do AP, “em termos de conteúdos de Física, de aspectos teóricos, metodológicos e epistemológicos do ensino da Física, e do uso de novas tecnologias no ensino de Física”, ou seja, são oportunizados saberes da formação profissional, ou acadêmicos, que devem ser integrados aos saberes já existentes (INSTITUTO DE FÍSICA, 2009). Durante a análise dos enunciados, evidenciaram-se situações em que existem saberes oriundos da formação profissional que não encontram lugar na prática profissional dos APs, pois não foram evidenciados em suas falas (como teorias de ensino-aprendizagem), enquanto outros são passíveis de integração, como, por exemplo, os saberes relacionados às novas tecnologias. Os resultados parciais, apresentados neste trabalho, não esgotam a pesquisa, pois o impacto do MP é um assunto complexo que demanda um maior entendimento por parte de professores e formadores. Ao investigar o impacto do MPEF na vida profissional dos APs, será possível compreender os limites e as possibilidades dessa modalidade de formação, contribuindo para melhor qualificar os profissionais que atuam na educação básica em nosso país.

\section{NOTAS}

${ }^{1}$ Diretoria de Avaliação (DAV) da Coordenação de Aperfeiçoamento de Pessoal de Nível Superior (CAPES).

${ }^{2}$ Elaborada pela CAPES/DAV.

${ }^{3}$ Assumimos, neste caso, em consonância com Porlán, que o termo epistemológico está associado "ao conjunto de idéias e formas de atuar que têm os professores, que guardam relação mais ou menos direta com o conhecimento escolar e com seu processo de construção e facilitação, sejam estas idéias de um nível mais epistemológico-filosófico estrito, psicológico, didático-currícular, metodológico, experimental, etc., ou se manifestem de forma mais ou menos tácita ou explícita" (PORLÁN et al. 1997, p.161).

${ }^{4} \mathrm{NI}$ - não informado ou não recorda. 
${ }^{5}$ Privado (Priv.) - Instituição de Ensino Privado ou Particular, Público (Públ.) - Instituição de Ensino Público Municipal, Estadual ou Federal.

${ }^{6}$ Média aritmética em relação aos vinte informantes.

\section{REFERÊNCIAS}

BAKHTIN, M. M. Estética da criação verbal. $4^{a}$ Edição. São Paulo: Martins Fontes, 2003. 476 p.

BAKHTIN, M. Marxismo e filosofia da linguagem. 12 Edição. São Paulo: HUCITEC, 2006. 201 p.

BORGES, G.; REZENDE, F. Vozes epistemológicas Pedagógicas nos Parâmetros Curriculares Nacionais de Biologia. ALEXANDRLA Revista de Educação em Ciência e Tecnologia, v.3, n.2, p.1-16, jul. 2010.

BRASIL(a). Portaria normativa $n^{\circ} 7$, de 22 de junho de 2009. Dispõe sobre o mestrado profissional no âmbito da Fundação Coordenação de Aperfeiçoamento de Pessoal de Nível Superior - CAPES. Diário Oficial da República Federativa do Brasil, Brasília, DF, n. 117, 23 jun. 2009.Seção I, p.31-32.

BRASIL(b). Portaria normativa ${ }^{\circ} 17$, de 28 de dezembro de 2009. Dispõe sobre o mestrado profissional no âmbito da Fundação Coordenação de Aperfeiçoamento de Pessoal de Nível Superior - CAPES. Diário Oficial da República Federativa do Brasil, Brasília, DF, n. 248, 29 dez. 2009.Seção I, p. 20-21.

CAPES. Diretoria de Avaliação (DAV). Ficha de avaliação de Programa de Mestrado Profissional Triênio: 2008-2010. Brasília, DF: CAPES, 2008.

CONTRERAS, J.A. A autonomia de professores. São Paulo: Editora Cortez, 2002. 144p.

FISCHER, T. Mestrado profissional como prática acadêmica. RBPG. Revista Brasileira de PósGraduação, v. 2, n.4, p.24-29, jul. 2005.

GUIMARÃES, G. M. A., ECHEVERRIA, A. R., MORAES, I. J. Modelos didáticos no discurso de professores de ciências. Investigação em Ensino de Ciências. Porto Alegre, v.11, n.3, p. 303-322, dez. 2006.

INSTITUTO DE FÍSICA DA UNIVERSIDADE FEDERAL DO RIO GRANDE DO SUL. Mestrado Profissional em Ensino de Física. Disponível em: <http://www.if.ufrgs.br/ppgenfis/index. php>. Acesso em: set. 2009.

NEGRET, F. A identidade e a importância dos mestrados profissionais no Brasil e algumas considerações para a sua avaliação. RBPG - Revista Brasileira de Pós-Graduação, v. 5, n.10, p.217-225, dez. 2008.

OSTERMANN, F.; REZENDE, F. Projetos de desenvolvimento e de pesquisa na área de ensino de ciências e matemática: uma reflexão sobre os mestrados profissionais. Caderno Catarinense de Ensino de Física. v.26, n.1, p. 66-80, abr. 2009.

PORLÁN, R.; RIVERO, A. El conocimiento de los profesores. Sevilla: Díada, 1998.

PORLÁN, R.; RIVERO, A.; MARTÍN, R. Conocimiento profesional y epistemología de los professores I: Teoría, métodos e instrumentos. Enseñanza de las ciencias, v. 15, n.2, 155-171, 1997.

RECHDAN, M.L.de A. Dialogismo ou polifonia? Revista Ciência Humanas, v. 9, n. 1, Setembro, 2003. Disponível em: <site.unitau.br/scripts/prppg/humanas/index.htm>. Acesso em: maio 2011.

SOCORRO, M. do MACEDO, M. do S. A. N.; MORTIMER, E. F. Perfil dos professores do primeiro ciclo; questões socioculturais e pedagógicas. Revista Brasileira de Estudos Pedagógicos, Brasília, v.87, n. 215,29-43, jan/abril. 2006.

TARDIF, M.; LESSARD E GAUTHIER, C. Formação dos professores e contextos

sociais. Porto, Portugal: Rés editora, 2001

TARDIF, M. Saberes docentes e formação profissional. $8^{a}$ ed. Petrópolis, RJ: Ed. Vozes, 2007.

WERTSCH, J. V. Voices of the mind: a sociocultural approach to mediated action. Cambridge, Mass. Harvard University Press, 1991. 170 p. 